\title{
Defeasibility in Judicial Opinion: Logical or Procedural?
}

\author{
DAVID M. GODDEN \\ DOUGLAS WALTON
}

\author{
David M. Godden \\ Department of Philosophy \\ University of Winnipeg \\ 515 Portage Avenue \\ Winnipeg, Manitoba \\ Canada R3C 2B9 \\ d.godden@uwinnipeg.ca
}

\author{
Douglas Walton \\ Department of Philosophy \\ The University of Winnipeg \\ Winnipeg, Manitoba \\ Canada R3B 2E9 \\ d.walton@uwinnipeg.ca
}

\begin{abstract}
While defeasibility in legal reasoning has been the subject of recent scholarship, it has yet to be studied in the context of judicial opinion. Yet, being subject to appeal, judicial decisions can default for a variety of reasons. Prakken (2001) argued that the defeasibility affecting reasoning involved in adversarial legal argumentation is best analysed as procedural rather than logical. In this paper we argue that the defeasibility of ratio decendi is similarly best explained and modeled in a procedural and dialectical framework. We propose that appeals are best understood as meta-dialogues about the reasoned dialogue occurring in the initial trial.
\end{abstract}

Résumé: Malgré les études récentes sur la défaisabilité dans le raisonnement légal, on ne l'a pas encore étudiée dans le contexte de l'opinion judiciaire. Une décision judiciaire, quoique sujette à un jugement en appel, peut être défaite pour une variété de raisons. Pakken (2001) a soutenu qu'une analyse procédurale de la défaisabilité d'un raisonnement dans une argumentation légale antagoniste est meilleure qu'une analyse logique. De façon semblable, un encadrement procédural et dialectique explique et illustre mieux la défaisabilité de ratio decendi. Nous proposons que des jugements en appel soient mieux entendus comme des méta-dialogues sur les raisonnements avancés dans le procèsmêm

Keywords: defeasibility, judicial opinion, legal reasoning, meta-dialogue, opentextured, ratio decendi

\section{Introduction}

The idea that there is a distinctive type of legal reasoning (Ellsworth 2005) has inspired theorists of both law and argumentation to provide 
viable explanatory models of it. There is a strong concurrence among theorists that a characteristic feature of legal reasoning is that it is in some sense defeasible. Yet, there is less agreement concerning the proper explanation of the nature, source and operation of this defeasibility. Recent efforts on this topic have viewed it in the context of adversarial argumentation-the making and presenting of cases at trial. In this context, Prakken (2001, p. 269) has argued that, because defeasibility in adversarial legal argument involves dialectical roles and (potentially shifting) allocations of burdens of proof, defeasibility in (adversarial) legal reasoning is properly analysed as procedural rather than logical.

In this paper, we consider a different dimension of defeasibility in law, as it occurs in judicial opinion-that is, in the reasoned arguments offered by judges as part of their decisions. In this situation, the obviously dialectical features of argumentation are absent. Instead of two parties engaged in an argumentative dialogue where the burden of proof can shift back and forth between disputants, we have a situation where a single reasoner has provided a justification or rationale for a decision. Yet, it remains the case that judicial opinions are defeasible: they can be overturned on appeal or sent back to a trial court for retrial. What is the best perspective by which to analyse this dimension of the defeasibility of legal reasoning? ${ }^{1}$

We begin by providing a brief overview of existing treatments of defeasibility in legal reasoning. Following this, we consider the possible grounds, outcomes and legal procedures affecting the appeal of legal decisions to determine which explanatory model best fits the type of defeasibility affecting judicial opinion.

\section{Defeasibility in law: An overview}

It is typically held (MacCormick 1978, p. 37 and Ch. 2 passim; Golding 1984, 35-42; Hage 2003, p. 230) that at least some instances of reasoning used in law are correctly analysed as deductive. Indeed, both statutory law and the legal authority ${ }^{2}$ arising from precedent in common law can be articulated as rules and expressed in the form of conditionals of the form If $p$ then $q$ (Twining and Miers 1999, pp. 131-134; MacCormick 1978, p. 45). It might seem, then, that legal rules can be treated

\footnotetext{
${ }^{1}$ For the remainder of the paper we restrict our use of the term 'legal reasoning' to apply only to cases of judicial opinion. Golding (1984, p. 1) specifies this narrow sense of the term, whereby: “'legal reasoning' refers to the arguments that judges give ... in support of the decisions they render. These arguments consist of the reasons for the decisions, and these reasons are intended as justifications for the decisions.”

${ }^{2}$ In the practice of law, the justification of a decision by precedent is often indicated by saying, with reference to a line of cases treated as precedents, "there is authority for saying that $q$ [based on those precedents whose operative facts were $p$ ]." In this paper, we use the phrase "legal rules" to indicate both statute law and the authority of precedent.
} 
straightforwardly as material conditionals of the form $p \supset q$, and that legal reasoning roughly has the form of modus ponens: "whenever certain operative facts occur, a given legal consequence follows" (MacCormick 1978, p. 67).

\subsection{Sources of defeasibility in legal reasoning}

There are several features of the law which prevent this type of deductive analysis of legal reasoning in many cases. First, the operative facts entered into evidence at trial may over-determine the legal outcome by, for instance, triggering conflicting rules whose consequences are mutually inconsistent. Here, it will have to be determined which legal rule(s) ought to trump the other(s), and fundamental legal principles like justice and fairness may apply. In this way, legal arguments may be rebutted (Pollock, 1970) or overridden (Pinto, 2001) by stronger arguments for opposite conclusions.

Second, many of the conditionals expressing legal rules are not universal, but are subject to defeat in certain types of circumstances, e.g., when exclusionary conditions apply. In this way, legal arguments may be undercut (Pollock, 1970) or undermined (Pinto, 2001) by operative facts which defeat the inference at work in the argument. Thus, MacCormick (1995, p. 103) describes all legal rules as only "ordinarily necessary and presumptively sufficient.”

\subsection{Inferential models of defeasibility in legal reasoning}

To accommodate this second feature, Sartor (1995, p. 121) has proposed that the conditions pertaining to legal rules include both probanda (or elements to be proved) and non-refutanda (or elements not to be refuted). On this analysis, legal rules are not like material conditionals but rather have the form If $p_{1}$ and ... and $p_{i}$ and $\left\langle r_{j}>\right.$ and $\ldots<r_{n}>$ then $q$, whereby "a norm condition must be considered satisfied if every probandum $[p]$ contained in that norm antecedent has been derived in the accepted justification context, and no non-refutandum $[<r>]$ included in that antecedent has been refuted" (Sartor 1995, p. 121). This allows inferences to be presumptively drawn in the absence of countervailing considerations which, if determined to obtain at some later point could, nevertheless, defeat the original inference. Sartor (1995, p. 122-130) argues that such a formulation is able to represent a variety of legal ideas including: constitutive vs. impediment facts; presumed vs. non-presumed facts; facts to be proved vs. facts for which there must not be proof to the contrary, and facts about which the plaintiff bears the burden vs. facts about which the defendant bears the burden. The idea that defeating conditions can be explicitly stated as non-refutanda captures MacCormick's (1995, p. 100) notion of express defeasibility.

Yet, it is generally agreed that it is not possible to explicitly give all the defeating conditions for some rule. Rather, as MacCormick (1995, 
p. 103) writes, "Law has to be stated in general terms, yet conditions formulated generally are always capable of omitting reference to some element which can turn out to be the key operative fact in a given case." Thus, legal rules must also be understood as implicitly defeasible (MacCormick 1995, p. 104), "limited not only by specific exceptions but by indeterminate and estimated provisions" (Sartor 1995, p. 141). This third source of defeasibility seems to indicate that we cannot expect a fully formalized system of defeasible legal reasoning, but instead that some relevant conditions governing the application of a legal rule can only be identified after the fact.

This third sense of defeasibility in law is standardly traced back to H.L.A. Hart's (1948-49) essay "The Ascription of Responsibility and Rights.” There (p. 173) Hart argued that the definition of a legal concept cannot be given "by the provision of a verbal rule for the translation of a legal expression into other terms or one specifying a set of necessary and sufficient conditions.” This notion matured in Hart's later works (1958, 1961 ) into the idea that the concepts of ordinary language are 'opentextured' such that, while there is a core meaning (exemplified by paradigmatic and constitutive examples), there will be a 'penumbra' of cases where it is not certain whether the concept properly applies. "Fact situations do not await us neatly labeled, creased, and folded, nor is their legal classification written on them to be simply read off by the judge" (Hart 1958, p. 607). Because of this, legal reasoning cannot properly be analysed as deductive because "Logic is silent on how to classify particulars - and this is the heart of a judicial decision" (ibid., p. 610). Under this analysis, defeasibility is the result of a certain kind of indeterminacy: there is a conceptual indeterminacy in the classification of cases which produces a rule-indeterminacy when rules involving some open-textured concept are applied to cases in the conceptual penumbra.

MacCormick (1978, pp. 65-67) has shown how this type of indeterminacy can be analysed as a problem of ambiguity among legal rules, and the problem of classification becomes a problem of interpreting the law. MacCormick considers an example ${ }^{3}$ where the law (roughly) states: [L] "If a person discriminates against another on the ground of national origins, then he discriminates unlawfully," and a judge is required to rule on a case where a housing board has denied applications on the basis of legal nationality. Such a case seems to hang on whether the law is rightly interpreted to say [L'] "if a person discriminates against another on the ground of national origins (including a person's legal nationality) then he discriminates unlawfully", or [ $\left.\mathrm{L}^{\prime \prime}\right]$ "if a person discriminates against another on the ground of national origins (as distinct from that person's legal nationality), then he discriminates unlawfully.” In effect then, even when stated complete with all its explicit probanda and non-refutanda, a legal rule can remain ambiguous between two conditionals of the forms [ $\left.\mathrm{L}^{\prime}\right]$ If $\boldsymbol{p}_{1}{ }^{\prime}$ and ... and

\footnotetext{
${ }^{3}$ Ealing Borough Council London v. Race Relations Board ([1972] A.C. 342)
} 
$p_{i}$ and $<r_{j}>$ and $\ldots<r_{n}>$ then $q$ and [L"] If $\boldsymbol{p}_{1}$ " and ... and $p_{i}$ and $<r_{j}>$ and $\ldots<r_{n}>$ then $q$. Importantly, the reasoning involved in determining this issue of interpretation will be part of the ratio decendi of the case, and will not be deductive in nature (MacCormick 1978, p. 67-68). ${ }^{4}$

The primary way, then, that defeasibility in law has been modeled is logically, or inferentially, as a type of reasoning involving some form of defeasible conditional. This defeasibility does not always arise in the way standardly envisioned by non-monotonic logic (where additional information defeats a previously licensed inference), but the prevailing view seems to be that other forms of defeasibility can be modeled inferentially as well.

Normally in the literature on defeasibility, this term is taken to refer to the kind of situation in which a new premise is added to an argument, and the addition of that new premise makes the argument default, so that the conclusion can no longer be drawn (Prakken and Sartor 2004). However, our way of defining defeasibility makes it wider than the traditional notion. On our way of defining it, defeasibility also includes cases where the deletion or modification of an old premise in an argument makes the argument default, so that the conclusion can no longer be drawn. For example, we would include under the heading of defeasibility a case where one premise is a generalization that has to be modified where new information comes in stating an exception to the rule posited by the generalization.

Some would say that the kinds of cases we allow under the heading of defeasibility should instead come under the heading of belief revision, or perhaps theory revision. However, there is also some uncertainty on whether the modification of an old premise required by a new information positing an exception to a generalization should come under the heading of defeasibility or not. Many authors would include this kind of case under the heading of defeasibility. Indeed, the typical Tweety example, 'Birds fly, Tweety is a bird, therefore Tweety flies', is generally treated as an instance of defeasible reasoning rather than as an instance of belief revision. On our analysis, all three kinds of defeasibility share a common basis, as all fit the dialogue model in which an argument needs to be seen as a move that may need to be modified as the dialogue proceeds and new arguments or information come in. As new arguments come in to the dialogue, on our model, premises of old arguments will have to be modified or given up, and conclusions of old arguments will have to be retracted because they have now been cast into doubt by the new arguments.

\footnotetext{
${ }^{4}$ MacCormick analyses this as an ambiguity between two deductive rules: If $p$ 'then $q$ and If $p$ "then $q$.
} 


\subsection{Types of defeasibility affecting legal reasoning}

Having considered some of the ways that legal rules are defeasible, we proceed to consider several explanations of the nature of that defeasibility and its operation. Hage (2003, 2005) distinguishes five kinds of defeasibility having application in the law:

ontological defeasibility: the defeat of a certain kind of legal fact, conceptual defeasibility: the defeat of the applicability of a (set of) legal concept(s) to a situation, epistemic defeasibility: the general fallibility and revisability of our beliefs and opinions, justification defeat: a form of belief revision which results from the defeat of our reasons or justifications for our beliefs, and

logical defeasibility: the defeasibility of conditionals expressing legal rules.

Hage argues that justification defeat can play an important role in legal reasoning, and that it is best represented through a non-monotonic logic of the sort found in logical defeasibility. We have also seen how conceptual defeasibility plays a role in legal reasoning, how it could explain ontological defeasibility, and how, though it cannot be fully expressed formally, seems amenable to an inferentially-based treatment.

MacCormick (1995, p. 102), using the language of rights, argues that it is neither legal facts nor the legal concepts which are properly described as defeated.

The 'right' is, after all, a theoretical object, an institutional fact. Such a fact exists only where there is a perfect and undefeated satisfaction of all conditions (the implicit as well as the explicit) actually required in a given case. It is the ascription of a right, or the asserting of a claim to it (or to what one purports to be entitled to by the right, e.g., payment of a widow's allowance), that can be defeated, not the right itself. So it is not after all the concept that is defeasible, but some formulated statement of conditions for instantiating the concept in given cases, or some assertion, ascription or claim based on a certain understanding of those conditions.

So it is perhaps best to understand all defeasibility in law as instances of justification defeat, whereby what is defeated is a claim (rather than a fact or a concept) whose reasons were undermined or overridden.

At this point it might seem as though, since the nature of defeasibility in law is almost entirely inferential, that the proper way to explain and model its operation is inferentially as well. Against this, Prakken (2001) and Prakken and Sartor (1996, 2004) have argued that defeasibility in law should be modeled dialectically. Prakken and Sartor 
(2004) describe three primary types of defeasibility in law: inferencebased defeasibility, theory-based defeasibility, and process-based defeasibility. Theoretical defeasibility is distinguished from inferential defeasibility because "it concerns the holistic choice between theories, rather than the use of a [single] theory" (p. 136). In their view, defeasibility in law is inherently process-based because it "provides the dynamic context in which inference-based and theory-based defeasible reasoning take place, through the interaction of multiple agents” (p. 137).

\section{Defeasibility in judicial opinion}

We now apply the foregoing considerations to the situation of judicial opinion. Golding (1984, pp. 8-9) holds that ratio decendi can serve the function of rational persuasion as well as guidance through the principle of stare decisis. He further observes that common principles familiar to informal logicians such as premise truth or acceptability, and relevance serve as evaluative standards. In regards to sufficiency, or the strength of the inferential link between the premises and conclusion of a judicial opinion, we hold that something less than deductive validity is appropriate. As we noted at the outset, being subject to review on appeal, there can be little doubt that judicial opinions are defeasible in some sense, and therefore call for evaluative standards that reflect this inherent quality of them.

The question is: which theoretical framework provides the best explanatory model for this type of defeasibility in law? To answer this question, we first consider the possible grounds that might justify an appeal.

\subsection{Grounds for Appeal ${ }^{5}$}

In both civil and criminal matters, there are generally three distinct types of grounds for initiating an appeal proceeding. In the initial trial (1) there was some error of process, or (2) there was some error of law, or (3) subsequent to the initial trial, new facts not known or reasonably discoverable at the time of trial have come to light which could conceivably have had a bearing on the outcome of the initial trial. ${ }^{6}$

\footnotetext{
${ }^{5}$ Due to the space limits of this paper we only consider defeasibility of judicial opinions in Anglo-American legal systems. As was observed by one of our anonymous referees, in several continental legal systems, appeal procedures work differently; for example in some instances appeal of the entire case is considered, including factual issues.

${ }^{6}$ While we often hear about this last type of case in the media, as for example when a jailhouse informant recants his testimony or scientific advances allow for the testing of DNA evidence not possible at the time of trial, it should be noted that is somewhat of a rara avis in the normal course of the law. There is a strong professional and legal duty on counsel to be thoroughly diligent in preparing and presenting their cases at trial, and appeals are seldom granted on the basis of "oh, we forgot to mention < some pertinent
} 
Errors of process occur when a trial judge does not conduct a trial fairly or properly, and can be the result of mistakes or can indicate a(n apparent) lack of objectivity on the part of the presiding judge. Examples include the failure to ensure that witnesses are properly dealt with, the unbalanced summarizing of the evidence presented at trial, or the giving of faulty instructions to the jury. Errors of law occur when a court reaches the wrong conclusion on the basis of law, and are typically said to be the result of a trial judge 'misdirecting himself as to the law.' Examples include the failure of a trial judge take into account material facts in evidence that would have a bearing on the outcome of the case, his failure to recognize a prevailing line of cases when apparently conflicting precedents exist, or his rendering a decision which is ultra viries (exceeding the bounds of the court's power in some respect).

Importantly, neither of these two types of defeasibility normally involves any change to the factual information (the premises) on which the legal decision was made. Indeed, it is not the job of appellate courts to re-examine evidence or to make (new) determinations of findings of fact. Thus, the predominant types of defeasibility pertaining to judicial opinion do not arise from the addition or deletion of premissory information, and therefore cannot be represented through the logical defeasibility of some kind of non-monotonic logic. Rather, the defeasibility of judicial opinion in these types of cases involves the misapplication of (or outright failure to apply) legal rules which ought to have been applied (in the case of errors of law), or the failure to follow proper legal procedure. While the first of these types of errors can perhaps be modeled and explained at a purely inferential level, we note that the latter of these is inherently procedural and seems to call for a procedural or even dialectical treatment of the defeasibility arising therefrom.

That said, the legally permissible introduction of genuinely new and probative information can provide grounds for appeal, and fits standard logical notions of defeasibility whereby the introduction of new information occasions the retraction of a previously deduced conclusion. Further, some errors of procedure can affect the evidence before the court on the basis of which the initial judgment was made. For example, if a trial judge allowed the results of an illegal search warrant into evidence, then certain operative facts may have been considered in his reaching a judgment when they ought not to have been. Alternately, if a trial judge did not allow the opinion testimony of a properly accredited expert witness, then certain evidence which ought to have been considered in his reaching a judgment would not have been not so considered. In these types of cases, the evidence at trial and the findings of fact there made, may be reviewed on appeal. This type of defeasibility, whether occurring as a result of the introduction of new information (non-monotonic

fact or precedent>"-type grounds where information that was available at the time of trial is later sought to be introduced during appeal. 
justification) or the retraction of previously admitted information (justification defeat) seems more straightforwardly inferential rather than procedural. This might be taken to indicate that some types of defeasibility affecting judicial opinion can be modeled and explained as purely monolectical and logical without involving dialectical or procedural theoretical tools.

Indeed, it is important to note that, at the centre of all types of defeasibility affecting judicial opinion that do not involve outright bias, there is some defeasible or otherwise faulty inference. That is, the ratio decendi of the case will somehow be erroneous. This might result from a variety of factors familiar to every informal logician, for example: its relying on faulty premises (mistaken findings of fact), or its failure to rely on pertinent premises (missing information or ignored evidence), or its relying on a faulty link between its premises and its conclusion (misapplication of, or failure to apply, a legal rule), or its not giving sufficient weight to arguments to a contrary conclusion. Purely procedural errors which could not conceivably have affected the outcome of the trial-which could not somehow result in a misapplication of the law in the case at hand-are not sufficient to defeat the initial finding of the court.

That said, we hold that the best explanatory model for the defeasibility of judicial opinion is procedural and dialectical. The reason is not merely that some of the sources of defeasibility cannot be explained in purely logical and monolectical terms. Many types of defeasibility in law are inferential in that they are either conceptual, logical or justificatory in nature. But even in these cases, defeat itself occurs through a set of legal procedures which are inherently dialectical and which play an important and irreducible part in explaining the operation of defeasibility in legal reasoning.

\subsection{The explanatory role of the appeal process}

Judicial opinion is only subject to defeat as a result of an appeal, ${ }^{7}$ and this appeal process cannot be explained purely inferentially but is inherently procedural and dialectical.

This process begins with the filing of an application with the court requesting leave to appeal. This application is reviewed by a judge to determine whether there are sufficient grounds for an appeal on the basis of whether there is any reasonable likelihood that the appeal might be successful. Should leave to appeal be granted, oral and written arguments are presented before a (panel of) judge(s) by all parties involved in the appeal. Appeals, then, are initiated by submissions-

\footnotetext{
${ }^{7}$ We ignore situations where new legislation would change the future course of legal decisions, as this does not (again, with rare exception) occasion the defeat of previously decided cases. Also, we only consider those aspects of the appeal judgement which form the ratio decendi, ignoring those parts of the judgement which may be obiter dicta or form part of a dissenting opinion.
} 
which can be treated as speech acts-and proceed by a series of submissions (treated as other speech acts) made by the participants to the appeal. Unlike in cases at the trial level, appeal judges can involve themselves much more directly and actively in the argumentative dialogue that occurs in an appeal hearing, by questioning and even challenging and raising objections to the parties making arguments. Also, during the appeal hearing there is no (or at least rarely) presentation of evidence (e.g., the calling of witnesses); instead the 'subject matter' of the argumentation during appeal is provided by a record of the proceedings of the initial trial (compiled in a trial record), including the original pleadings (in a civil case), the filing of charges (in a criminal case), any motions filed through the case, transcripts of the trial itself, and of course the judgments giving the findings of the trial court and its decision. Decisions at appeal will be based only on the material and arguments presented before the court, or adduced in the dialogue between counsel and the court. Thus, the results of an appeal are inherently a product of the processes that produced them. Features that are procedurally excluded, such as the second-guessing of a finding of fact made by the trial court, or arguments not presented by the parties to the appeal, can make no contribution to the outcome of the appeal proceedings, and hence to the defeat of judicial opinion.

Importantly, while there is no legal burden of proof (which, properly speaking, applies to issues of fact) applicable in appeal proceedings, there is an argumentative burden which must be met by the (prospective) appellant at each stage of the proceedings. The effect of this is similar to the burden of persuasion in that the appellant bears the risk of non-persuasion should the judge(s) fail to be persuaded by her arguments.

Prakken (2001, p. 269) found these two components-the dialectical roles of the participants, and the allocation of argumentative burdens - sufficient to conclude that the defeasibility of reasoning in adversarial legal argumentation is best analysed dialectically. So, since these same features are inherent in the defeat of judicial opinion through appeal, if Prakken was correct in his conclusions then the same ought to be said of defeasibility in judicial opinion.

Yet, more can be said. There are four possible outcomes of an appeal which has been heard by the court: (i) the original decision and ratio decendi can be upheld (affirmed); (ii) the decision can be upheld but for reasons different from those given in the ratio decendi; (iii) the decision can be overturned (reversed on appeal); or (iv) the case can be sent back to a trial court for retrial. All but the first of these indicates some form of defeat of the original judicial opinion. Yet each of these forms of defeat result from the conclusions of appellate court judges. Further, the decisions of appellate courts are binding not merely because of the reasons given but also because of the authority vested in the courts. Finally, when a case is sent back for retrial at the trial court, the trial- 
level dialogue is begun afresh, new evidence is admissible and previous findings of fact may be subject to defeat.

\subsection{The nature of a dialogic explanatory model}

When we claim that the best explanatory model for the defeasibility of judicial opinion is procedural and dialectical, we refer to the notion of a formal system of dialogue as defining these concepts. A dialogue has three parts, a start point, a sequence of moves, and an end point. During the sequence of moves, the participants in the dialogue take turns in an orderly manner. The moves are paired as one party (the proponent) puts something forward and the other party (the respondent) reacts to what was previously put forward. At the start point there will already be certain conditions in place defining what each party has to prove or to do in order to succeed. Such a requirement is sometimes called the obligation of each party (Hamblin, 1970). In a persuasion dialogue it is called the burden of persuasion (Prakken and Sartor, 2006). Hamblin (1971, p. 130) defined a move as a triple $\langle n, p, l\rangle . n$ is the length of the dialogue, representing the number of moves made, $p$ is a participant, and $l$ is a locution. Below is an example of how a short dialogue with three moves in it looks in Hamblin's formal model. The first move is labeled as 0 , the second as 1 , and the third as 2 .

$$
\left\langle 0, P_{0}, L_{4}\right\rangle,\left\langle 1, P_{1} L_{3,}\right\rangle,\left\langle 2, P_{0}, L_{2}\right\rangle
$$

Participant zero puts forward locution 4 at move zero (the first move). Next, participant one puts forward locution three. At the third move, participant zero responds by putting forward locution two. For example, locution four might be the asking of a question, while locution three might be an assertion made, in answer to the question. Locution two might be the putting forward of an argument that gives a reason not to accept that answer. Such a finite sequence of this sort will always begin with move zero and end at some specific move (the end point) defined by conditions set at the at the start point.

\subsection{Appeal as meta-dialogue}

We have one hypothesis to put forward tentatively, concerning the first ground for initiating an appeal proceeding, namely that of an error of process. When another judge, let us call him judge 2, has to review an error of process that may have been committed by a judge in a trial, called judge 1, judge 2 has to examine the whole trial, or some part of it, in which judge 1 made a ruling. This framework involves a dialectical shift from one dialogue to another. First there is the earlier trial in which judge 1 made a ruling, based on the trial rules and procedures for that trial. Second, once the trial has been completed, judge 2 has to look at its 
records, and make a decision regarding the question of whether what actually happened in that trial met the procedures and rules for it. We think that the best way to frame such a judgment is to see it as one argument about another. The argument of judge 1 reached a conclusion in the dialogue framework of the first trial. Judge 2 had to take a broader view in which he looked at the whole of that trial, and then used the evidence of the transcript of it to formulate arguments about its procedural fairness and correctness. The argumentation of judge 2 needs to be viewed as taking place within a secondary dialogue. It is called a metadialogue, or dialogue about a prior dialogue. In such a case, we need to distinguish between a ground level dialogue and a secondary level dialogue about that ground level dialogue.

A primary dialogue is a framework of argumentation in which participants in some definable type of verbal exchange supposedly adhere to procedural rules they have agreed to follow. For example, in a standard type of case two participants might agree to take part in a critical discussion where the goal is that of resolving a conflict of opinions by rational argumentation. A dialogue of this sort can be called a ground level dialogue, as contrasted with a metadialogue, or secondary dialogue about the ground level dialogue (Krabbe, 2003, p. 83). Suppose there is a disagreement about the correctness of some moves in a ground level dialogue. To resolve the disagreement, another dialogue may then begin that moves to a metadialogue level to determine whether some argument or other kind of move in the first dialogue can be judged to be correct criteria (Hamblin, 1970; Krabbe 2003).

According to Wooldridge, McBurney and Parsons (2005), argumentation in dialogue is inherently meta-logical, meaning that it does not just involve the putting forward arguments at one level of dialogue, but also the making of arguments about these arguments at a higher level of dialogue. In a hierarchical argument system, in addition to a first level, there needs to be a second level where judgments can be made about the success or failure of attack and defeat of an argument that was brought forward at the first level. A second level encompasses the process of reasoning about the arguments that were used at the first level.

\section{Conclusion}

In this paper we considered the issue of defeasibility as it affects legal reasoning in judicial opinion as distinct from its affect on adversarial argumentation made at trial. We argued that this type of defeasibility in law is best explained and modeled as procedural instead of logical or inferential. This is not to say that the defeasibility of judicial opinion is not inferential in nature, but rather because its operation in law is inherently procedural. Wherever the decision of a trial court is defeated it is because that decision relied upon an inference that is somehow faulty or inapplicable to the actual case being decided. In rare situations, this 
defeat is occasioned by changes in the facts determined to be operative in the case. Thus, the standard logical accounts of defeasibility (due to premise retraction or non-monotonic inference) can only account for a fraction of decisions defeated on appeal. Much more common is the occurrence of some error in law or procedure which gave rise to a misapplication of the law to the facts in the case. These errors, while inferential in nature, become manifest through the process of appeal. Consequently, they are best explained procedurally as meta-dialogues which examine the correctness of the reasoning and argumentation which occurred in the trial-level dialogue.

Acknowledgements: Research for this paper was made possible by research grants from the Social Science and Humanities Research Council of Canada held by each author.

\section{References}

Ellsworth, Phoebe C. (2005). Legal reasoning. In Keith J. Holyoak, \& Robert G. Morrison (Eds.), The Cambridge Handbook of Thinking and Reasoning (685-703). Cambridge: Cambridge University Press.

Golding, Martin P. (1984). Legal Reasoning. New York: Alfred A. Knopf.

Hage, Jaap, (2003). Law and defeasibility. Artificial Intelligence and Law, 11, 221-243.

Hage, Jaap: (2005). Entry for Law and Defeasibility. In IVR Encyclopedia of Jurisprudence, Legal Theory and Philosophy of Law. Available online at http://www.ivr-enc.info/en/article.php?id=40 accessed Jan. 31, 2007.

Hamblin, C.L. (1970). Fallacies. London: Methuen.

Hamblin, C.L. (1971). Mathematical models of dialogue. Theoria, 37, 130-155.

Hart, H.L.A. (1948). The ascription of responsibility and rights. Proceedings of the Aristotelian Society, 49, 171-194.

Hart, H.L.A. (1958). Positivism and the separation of law and morals. Harvard Law Review, 71, 593-629.

Hart, H.L.A. (1961). The Concept of Law. Oxford: Clarendon Press.

MacCormick, Neil. (1978). Legal Reasoning and Legal Theory. Oxford: Clarendon Press.

Krabbe, Erik C.W. (2003). Metadialogues. In Frans H. van Eemeren, J. Anthony Blair, Charles A. Willard and A. Francisca Snoek Henkemans (Eds.), Anyone Who Has a View: Theoretical Contributions to the Study of Argumentation (pp. 83-90). Dordrecht: Kluwer. 
MacCormick, Neil. (1995). Defeasibility in law and logic. In Z. Bankowski, et al. (Eds.), Informatics and the Foundations of Legal Reasoning (99-117). Dordrect: Kluwer.

Pinto, R.C. (2001). Argument schemes and the evaluation of presumptive reasoning. In Argument Inference and Dialectic (pp. 98-104). Dordrecht: Kluwer.

Pollock, John L. (1970). The structure of epistemic justification. American Philosophical Quarterly, monograph series 4, 62-78.

Prakken, Henry. (2001). Modelling defeasibility in law: Logic or procedure? Fundamenta Informaticae, 48, 253-271.

Prakken, Henry \& Sartor, Giovanni. (1996). A dialectical model of assessing conflicting arguments in legal reasoning. Artificial Intelligence and Law, 4, 331-368.

Prakken, Henry \& Sartor, Giovanni. (2004). The three faces of defeasibility in the law. Ratio Juris, 17, 118-139.

Prakken, Henry \& Sartor, Giovanni. (2006). Formalizing arguments about the burden of proof. Proceedings of the International Conference on Artificial Intelligence and Law, ICAIL 07, Palo Alto, California.

Sartor, Giovanni. (1995). Defeasibility in legal reasoning. In Z. Bankowski, et al. (Eds.), Informatics and the Foundations of Legal Reasoning (pp. 119-157). Dordrect: Kluwer. [Also published in Rechtstheorie, 24, 1993, 281-316.]

Twining, William \& Miers, David. (1999). How to Do Things with Rules, $4^{\text {th }}$ ed. London, Butterworths.

Wooldridge, M., McBurney, P., \&Parsons, S. (2005). On the meta-logic of arguments. In Proceedings of the Fourth International Joint Conference on Autonomous Agents and Multi-Agent Systems (pp. 56-567). Utrecht. 